\title{
CURRENT OPINION
}

\section{Pertussis is increasing in unimmunised infants: is a change in policy needed?}

\author{
Sarath Ranganathan, Robert Tasker, Robert Booy, Parviz Habibi, Simon Nadel, \\ Joseph Britto
}

Paediatric Intensive Care and Paediatric Infectious Diseases

Units, Department of Paediatrics, St Mary's Hospital Medical School at Imperial College, London W2 1NY, UK

S Ranganathan

P Habibi

S Nadel

J Britto

Paediatric Intensive Care Unit, Great Ormond Street Hospital for Children NHS Trust, London WC1N 3JH, UK $\mathrm{R}$ Tasker

Department of Epidemiology, Institute of Child Health, University College London WC1N 1EH, UK R Booy

Correspondence to: Dr Britto.

email: j.britto@ic.ac.uk

Accepted 24 November 1998

\begin{abstract}
The proportion and trend in absolute number of pertussis notifications in young infants has increased each year in England and Wales since the accelerated immunisation schedule was introduced. We report five infants all less than 3 months of age admitted with life threatening pertussis infection to two paediatric intensive care units. Despite aggressive cardiorespiratory support measures, three of the infants died. Pertussis remains a significant cause of morbidity and mortality in unimmunised infants. In this age group presentation is likely to be atypical and infection more severe. Public health measures to prevent the disease could be strengthened. Chemoprophylaxis should be offered to susceptible contacts and booster vaccinations against pertussis considered.
\end{abstract}

(Arch Dis Child 1999;80:297-299)

Keywords: pertussis; Bordetella pertussis; chemoprophylaxis; immunisation

Although the current rate of immunisation uptake is high (estimated at about 93\%), ${ }^{1}$ Bordetella pertussis continues to cause significant morbidity and mortality. ${ }^{2}$ Pertussis is frequently underreported as although culture is very specific it is at best $80 \%$ sensitive. $^{3}$ The total morbidity and mortality from infection with this organism may be greatly underestimated.

Infants below the age of vaccination are now the population most at risk in countries with high uptake of pertussis vaccine. ${ }^{4}$ We report five consecutive infants less than 3 months of age admitted with pertussis to two paediatric intensive care units between October 1996 and May 1997.

\section{Case reports}

Table 1 summarises the clinical features of the five cases. Cases 1 and 4 were in contact with children who had culture positive pertussis. Family members of cases 3 and 5 had concurrent, paroxysmal cough. In these four cases chemoprophylaxis had not been given and unvaccinated, susceptible infants were exposed. Despite the use of advanced cardiorespiratory support measures, which included surfactant, high frequency oscillatory ventilation, nitric oxide, and extracorporeal membrane oxygenation, three infants died suggesting that if infants require mechanical ventilation for severe lung disease following pertussis infection then the mortality is high.

\section{Discussion}

The age distribution of infection with $B$ pertussis has changed as vaccine coverage has risen since the late 1970s. ${ }^{1}$ The proportion and

Table 1 Clinical details of five infants presenting with pertussis

\begin{tabular}{|c|c|c|c|c|c|c|c|}
\hline Case & Age (weeks) & Presentation & Relevant history & $\begin{array}{l}\text { Antibiotic } \\
\text { prophylaxis to } \\
\text { close contacts }\end{array}$ & $\begin{array}{l}\text { Blood leucocytes } \\
\text { (lymphocytes) } \times \\
10^{9} / l\end{array}$ & $\begin{array}{l}\text { Duration of endotracheal } \\
\text { intubation, mode of respiratory } \\
\text { support } \mathbb{E} \text { outcome }\end{array}$ & $B$ pertussis cultured from \\
\hline 1 & 3 & $\begin{array}{l}\text { Fever, cough, poor } \\
\text { feeding, cyanosis }\end{array}$ & $\begin{array}{l}\text { In household contact } \\
\text { with cousin with a } \\
\text { culture positive } \\
\text { pertussis infection }\end{array}$ & Not given & $70.7(27.3)$ & $\begin{array}{l}18 \text { hours } \\
\text { Mechanical ventilation, } \\
\text { HFOV \& NO } \\
\text { Died }\end{array}$ & Nasal swab in cousin \\
\hline 2 & 5 & $\begin{array}{l}\text { Apnoeas } \\
\text { No cough/whoop }\end{array}$ & $\begin{array}{l}\text { Born prematurely at } \\
34 \text { weeks' gestation }\end{array}$ & Not given & $26(18.72)$ & $\begin{array}{l}2 \text { days } \\
\text { Mechanical ventilation, nasal } \\
\text { CPAP ( } 3 \text { weeks) } \\
\text { Survived }\end{array}$ & Nasal swab \\
\hline 3 & 2 & $\begin{array}{l}\text { Cough, apnoea, } \\
\text { vomiting, hypoxia, } \\
\text { bradycardia }\end{array}$ & $\begin{array}{l}\text { Concurrent, } \\
\text { paroxysmal cough in } \\
\text { parents }\end{array}$ & Not given & $18.1(11.8)$ & $\begin{array}{l}9 \text { days } \\
\text { Mechanical ventilation } \\
\text { Survived }\end{array}$ & Nasal swab \\
\hline 4 & 4 & $\begin{array}{l}\text { Cough, poor } \\
\text { feeding }\end{array}$ & $\begin{array}{l}2 \text { patients on ward } \\
\text { with culture positive } \\
\text { pertussis }\end{array}$ & Not given & $81.0(36.5)$ & $\begin{array}{l}36 \text { days } \\
\text { Mechanical ventilation } \\
\text { HFOV, ECMO } \\
\text { Died }\end{array}$ & Tracheal secretions \\
\hline 5 & 4 & Cough, hypoxia & $\begin{array}{l}\text { Concurrent, } \\
\text { paroxysmal cough in } \\
2 \text { older sibs }\end{array}$ & Not given & $63.0(23.0)$ & $\begin{array}{l}33 \text { days } \\
\text { Mechanical ventilation, ECMO } \\
\text { Died }\end{array}$ & Nasal swab \\
\hline
\end{tabular}


absolute number of cases in infants under 3 months of age is increasing. In 1991, 121 of $5201(2.3 \%)$ cases of $B$ pertussis notified in England and Wales were under 3 months of age compared to 92 of 2309 (4\%) in 1992, 186 of $4091(4.5 \%)$ in 1993,203 of $3964(5.1 \%)$ in 1994,146 of $1869(7.8 \%)$ in 1995, 204 of 2387 $(8.5 \%)$ in $1996,{ }^{5}$ and 344 of $2989(11.5 \%)$ in 1997 (Harding D, Communicable Diseases Surveillance Centre, personal communication, 1998). There is a rising trend in absolute numbers of cases in infants less than 3 months $\left(\mathrm{p}<0.00001, \chi^{2}\right.$ test for trend). Between 1995 and 1997 there were at least 18 deaths from pertussis in the UK, and $15(83 \%)$ of these were in infants less than 3 months (Miller E, personal communication, 1998).

All five patients in our series were less than 3 months of age. There is still significant morbidity and mortality in the younger age group. ${ }^{26}$ There is little placentally transferred passive immunity to pertussis, and as accelerated primary vaccination is not complete until 4 months of age, young infants are highly susceptible to pertussis if exposed. ${ }^{7}$ In addition these children are much more likely to require hospitalisation $(82 \%)$ and intensive care. ${ }^{6}$ The highest rates of major complications such as pneumonia $(25 \%)$, apnoea, seizures $(4 \%)$, and encephalopathy $(1 \%)$ are also found in children younger than 2 months, as is the highest mortality. ${ }^{26}$ None of the five infants in our series presented with the characteristic whoop or paroxysmal cough seen in older children, indeed case 2 presented with frequent apnoeas and no cough. At this age the presentation of pertussis tends to be with apnoea or similar to other respiratory tract infections, either of which could result in the diagnosis of pertussis not being considered and treatment being delayed. $^{8}{ }^{9}$

Pertussis is an occasional cause of sudden infant death. Polymerase chain reaction analysis identified $B$ pertussis in $18 \%$ of nasopharyngeal specimens taken from 51 children who died suddenly. ${ }^{10}$

Susceptibility of older children and adults to infection with $B$ pertussis and their role in its transmission to younger, unvaccinated infants has been well documented. ${ }^{11}$ Family members of cases 3 and 5 had concurrent, paroxysmal cough. More cases of pertussis occur in infants whose mothers have themselves had cough of at least seven days duration during the infant's incubation period than those without this family history, suggesting that mothers are a source of infection to their babies. ${ }^{11}$ Could a reduction in cases in infants under 3 months of age be brought about by the use of booster doses of pertussis? Since 1990 the accelerated immunisation schedule has been employed in the UK. Three doses of diphtheria, tetanus, and pertussis (DTP) vaccine are given at 2,3 , and 4 months. In the UK, in several other European countries (Ireland, Denmark, Spain), and in most developing countries no further booster doses are recommended after 1 year old. Without booster doses vaccine derived immunity declines over $6-10$ years ${ }^{12}$ and is unmeasurable by 12 years of age. ${ }^{13}$ Preschool booster doses of pertussis in this country could protect children during their ensuing school age years and more importantly reduce transmission of the disease to younger unvaccinated siblings. ${ }^{14}$ There may be a case for considering a pertussis booster for young teenagers when they normally receive diphtheria, tetanus, and polio. Because $B$ pertussis infection in adults is common and endemic some authors have advocated boosting adults. ${ }^{15}$ However, the side effect rates of whole cell vaccine in older children and adults are unacceptably high. In the UK an acellular preparation (acellular pertussis vaccine, Acel-B; Wyeth Laboratories, Maidenhead, Berks, UK) is available presently only on a named patient basis. A recently reported trial found that the efficacy of certain acellular vaccines was similar to that of the UK whole cell vaccine. Further, although there were no significant differences between the vaccine groups for serious adverse events, high fever and seizures were less frequent after acellular vaccines than the UK whole cell vaccine. ${ }^{16}$ Acellular pertussis vaccine (APV) was safe with good immunogenicity when administered to preschool children. ${ }^{17}$ In the United States, the American Committee on Immunisation Practices recommends primary immunisation at 2 , 4 , and 6 months of age, with two further boosters of DTP using APV at 12-18 months and $4-6$ years of age. ${ }^{18}$

Although our case 1 had been in contact with a cousin with culture positive pertussis infection and case 4 had been in contact with two patients on the same ward with culture positive infection, neither case had been given pertussis chemoprophylaxis. Delay in administering erythromycin as chemoprophylaxis to household contacts is known to be associated with an increased rate of secondary infection. ${ }^{19}$ Erythromycin protected newborn babies when pertussis was serologically confirmed or culture positive in their mothers. ${ }^{20}$ There are no controlled trials demonstrating that prompt treatment of the index case will result in decreased transmission to close contacts. However, while erythromycin treatment of cases has little effect on the clinical course of illness, it does render the individual culture negative. ${ }^{21}$ There are analytical studies that support the use of erythromycin treatment with prophylaxis. Sprauer et al found an association with delay beyond two weeks in initiation of treatment and prophylaxis and secondary spread to household contacts. $^{22}$ Erythromycin administered as chemoprophylaxis before the first secondary case significantly reduced the rate of secondary transmission within families in one study. ${ }^{23}$ In view of high secondary attack rates of up to $80-100 \%$ in families, ${ }^{22}$ we believe that erythromycin treatment and prophylaxis should be given to the index case and close contacts in all households where there are unimmunised or partially immunised children. This should be given before 21 days of onset of a primary case. ${ }^{24}$ Doses of erythromycin used have been $40-50 \mathrm{mg} / \mathrm{kg} /$ day for children and 250$500 \mathrm{mg} /$ day for adults in three divided doses for 10-14 days. ${ }^{24}$ Seven days' of erythromycin 
treatment has been shown to be as effective as 14 days' at eradicating carriage in cases. ${ }^{25}$ This shorter course may be especially attractive in adult contacts, in whom erythromycin is more likely to cause unpleasant side effects. ${ }^{25}$ However, blinded, randomised controlled trials are needed before erythromycin prophylaxis can be recommended for all contacts irrespective of their vaccination status, as is the current practice in the USA and Canada. ${ }^{26}{ }^{27}$ Future trials should consider the newer macrolide antibiotics as these have fewer gastrointestinal adverse effects and may decrease the risk:benefit ratio of prophylaxis. The use of shorter courses of erythromycin also needs to be evaluated.

In summary, the proportion of pertussis notifications in infants less than 3 months of age has increased each year in England and Wales since the accelerated immunisation schedule was introduced, and the absolute number in 1997 was the highest this decade. Young infants are particularly vulnerable to infection resulting in small but significant morbidity and mortality. In this age group presentation is likely to be atypical. Consideration should be given to the introduction of preschool booster vaccinations against pertussis in the UK to reduce transmission to younger unvaccinated siblings. We suggest prompt treatment of the index case and that chemoprophylaxis be administered to all household contacts where there are unimmunised or partially immunised children.

1 White JM, Fairley CK, Owen D, Mathews RC, Miller E. The effect of an accelerated immunisation schedule on pertussis in England and Wales. Commun Dis Rep CDR Rev 1996;6:R86-91.

2 Office of Population Censuses and Surveys. Mortality Statistics (series DH2) 1974-1994.

3 Patriarca P, Biellik R, Sanden G, et al. Sensitivity and specificity of clinical case definitions for pertussis. $A m \mathcal{F}$ Public Health 1988;78:833-6.

$4 \mathrm{Hampl} \mathrm{SD,} \mathrm{Olson} \mathrm{LC.} \mathrm{Pertussis} \mathrm{in} \mathrm{the} \mathrm{young} \mathrm{infant.} \mathrm{Semin}$ Resp Infect 1995;10:58-62.

5 Communicable Disease Statistics England and Wales. 1992-96. Series MB2 number 18-22. London: HMSO, 1992-96. Series MB2 number 18-22. London: HMSO,

Gordon $M$, Davies HD, Gold R. Clinical and microbiologi-
cal features of children presenting with pertussis to a Canadian pediatric hospital during an eleven-year period. Pediat Infect Dis f 1994;13:617-22.

7 Bass JW, Zacher LL. Do newborn infants have passive immunity to pertussis. Pediatr Infect Dis $\mathcal{F}$ 1989;8:352-3.
8 Heininger U, Stehr K, Cherry JD. Serious pertussis overlooked in infants. Eur f Pediatr 1992;151:342-3.

9 Scotomayor J, Warer L, McMillan J. Inaccurate diagnosis in infants with pertussis. Am $\mathcal{F}$ Dis Child 1985;139:724-7.

10 Heininger U, Stehr K, Schmidt-Schapfer G, et al. Bordetella pertussis infections and sudden unexpected deaths in children. Eur F Pediatr 1996;155:551-3.

11 Izurieta HS, Kenyon TA, Strebel PM, Baughman AL, Shulman ST, Wharton M. Risk factors for pertussis in young infants during an outbreak in Chicago in 1993. Clin Infect Dis 1996;22:503-7.

12 Grimpel E, Begue P, Anjak I, Njampeko E, Francois P, Guiso N. Long-term human serum antibody responses after immunisation with whole-cell pertussis vaccine in France. Clin Diag Lab Immun 1996;3:93-7.

13 Long SS. Pertussis. In: Nelson, ed. Textbook of Pediatrics, 15th ed. Philadelphia: WB Saunders, 1996:779-84.

14 Novelli V, Al Ansari H, Mok Q, Tasker R. Pertussis vaccination is there need for a booster dose? Lancet 1994;344: 1225-6.

15 Cherry JD. The role of Bordetella pertussis infections in adults in the epidemiology of pertussis. Dev Biol Standard. 1997;89:181-6.

16 Olin P, Rasmussen F, Gustafsson L, Hallander HO, Heijbel $\mathrm{H}$. Randomised controlled trial of two-component, threecomponent, and five-component acellular pertussis vaccine component, and five-component acellular pertussis vaccine 1997;350:1569-77.

17 Englund JA, Decker MD, Edwards KM, Pichichero ME, Steinhoff MC, Anderson EL. Acellular and whole-cell pertussis vaccines as booster doses: a multicenter study. Pediatrics 1994;93:37-43.

18 Hall CB. The recommended childhood immunization schedule of the United States. Committee on Infectious Diseases, American Academy of Pediatrics and Center for Disease Control. Pediatrics 1995;95:135-7.

19 Biellik RJ, Patriarca PA, Mullen JR, et al. Risk factors for community and household acquired pertussis during a large scale outbreak in central Wisconsin. F Infect Dis 1988; 157:1134-41.

20 Granstrom G, Sterner G, Nord CE, Granstrom M. Use of erythromycin to prevent pertussis in newborns of mothers with pertussis. F Infect Dis 1987;155:1210-14.

21 Bergquist S, Sverkr B, Dahnsjo H, Sundelof BO. Erythromycin in the treatment of pertussis: a study of bacteriological and clinical effects. Pediatr Infect Dis f 1987;6:458-61.

22 Sprauer MA, Cochi SL, Zell ER, et al. Prevention of secondary transmission of pertussis in households with early use of erythromycin. Am F Dis Child 1992;146:17781.

23 De Serres G, Boulianne N, Duval B. Field effectiveness of erythromycin prophylaxis to prevent pertussis within families. Pediatr Inf Dis f 1995;14:969-75.

24 Dodhia H, Miller E. Review of the evidence for the use of erythromycin in the management of persons exposed to pertussis. Epidemiol Infect 1998;120:143-9.

25 Halperin SA, Bortolussi R, Langley JM, Miller B, Eastwood BJ. Seven days of erythromycin estolate is as effective as fourteen days for the treatment of Bordetella pertussis infections. Pediatrics 1997;100:65-71.

26 Joint Statement by the National Advisory Committee on Immunisation, the Advisory Committee on Epidemiology and the Canadian Pediatric Society. Statement on management of persons exposed to pertussis and pertussis outbreak control. Can Commun Dis Rep 1994;20:193-9.

27 American Academy of Pediatrics. Pertussis. In: Peter G, ed. 1994 Red Book: Report on the Committee on Infectious Diseases, 23rd ed. Elk Grove Village, Illinois: American Academy of Pediatrics, 1994:335-75. 